\title{
Oversiktsartikkel
}

\section{Kirurgi ved kronisk venøs insuffisiens}

\begin{abstract}
Sammendrag
Bakgrunn. Kronisk venøs insuffisiens kan føre til invalidiserende plager i form av smerter, ødem, venøs klaudikasjon og leggsår. Konvensjonell behandling omfatter kompresjonsterapi med elastiske strømper, elevasjon av ekstremitetene ev. supplert med sanering av overflatiske insuffisiente åreknuter. I denne artikkelen blir kirurgisk behandling (dyp veneklaff-rekonstruksjon eller dyp veneklaff-transplantasjon) og endovaskulær behandling (perkutan rekanalisering av okkluderte posttrombotiske dype vener), for denne tilstanden presentert og diskutert.
\end{abstract}

Materiale og metode. Artikkelen er basert på et ikke-systematisk søk i PubMed-og Cochrane-databasene.

Resultater. Sårtilheling etter rekonstruktiv dyp venekirurgi rapporteres å kunne oppnås i 60-78\% av tilfellene og klinisk bedring hos $90 \%$ av pasientene. Median sårfri periode etter slik kirurgi synes å være lengre ved primær (medfødt, familiær belastning) kronisk venøs insuffisiens enn ved sekundær (etter dyp venetrombose) kronisk venøs insuffisiens (54 mot $18 \mathrm{md}$.). Venøs klaudikasjon og leggsår forårsaket av venøs obstruksjon behandles endovaskulært og i $90 \%$ av tilfellene oppnås rekanalisering av okkluderte dype vener.

Fortolkning. Rekonstruktiv dyp venekirurgi er et reelt behandlingsalternativ ved kronisk venøs insuffiens der konvensjonell terapi ikke har lyktes. Gevinsten er sårfrie perioder, symptombedring, tilbakeføring til arbeidslivet og økt livskvalitet.

\author{
Antonio Rosales \\ antonio.rosales@aus.no \\ Oslo vaskulære senter \\ Oslo universitetssykehus, Aker, 0514 Oslo \\ Carl-Erik Slagsvold \\ Oslo vaskulære senter og \\ Avdeling for sirkulasjonsfysiologi \\ Jørgen J. Jørgensen \\ Oslo vaskulære senter \\ Gunnar Sandbæk \\ Oslo vaskulære senter og \\ Intervensjonsradiologisk avdeling
}

Kronisk venøs insuffisiens med utvikling av leggsår representerer et alvorlig medisinsk og sosialt problem. Prevalensen av venøst leggsår rapporteres å være $0,1-1,0 \%(1,2)$. I Sverige er de årlige utgiftene relatert til behandling av venøse sår estimert til 73 millioner euro (3).

Konvensjonell behandling omfatter kompresjonsterapi med elastiske strømper, elevasjon av ekstremitetene ev. supplert med sanering av overflatiske insuffisiente åreknuter. Venøs obstruksjon behandles endovaskulært med rekanalisering og stenting.

Hos en liten andel av pasientgruppen med uttalte symptomer kan det foreligge indikasjon for dyp venøs rekonstruksjon. Nøye utredning med avbilding og venefysiologiske undersøkelser er nødvendig $(4,5)$. Indikasjoner for rekonstruktiv dyp venekirurgi er kronisk residiverende leggsår og invalidiserende plager som smerter og spreng etter belastning (venøs klaudikasjon) og hevelse $(6,7)$.

Hensikten med dyp venøs rekonstruksjon ved leggsår er å redusere det høye venøse trykket disse pasientene har distalt $\mathrm{i}$ beina under gange, ved å korrigere venøs refluks (unormal tilbakestrømning av blod gjennom veneklaffer). I denne artikkelen blir slik behandling presentert og diskutert.

\section{Materiale og metode}

Det er utført et ikke-systematisk søk i PubMed- og Cochrane-databasene basert på forfatternes erfaring innen feltet.

\section{Kirurgisk behandling}

Refluks i overflatiske vener og perforanter oppheves ved kirurgisk eksisjon eller ligatur av affiserte vener. Dyp venøs refluks krever enten kirurgisk reparasjon (klaffeplastikk) eller erstatning av de ødelagte klaffene (autotransplantasjon, ev. lokal kirurgisk konstruksjon av ny veneklaff ved bruk av veneveggens intima (neoklaff) (7-10) (fig 1-3). Dersom det foreligger insuffisient rekanalisering etter tidligere dyp venøs trombose, må slik venøs obstruksjon korrigeres før dyp venøs rekonstruksjon, hvor den vanligste prosedyren er endovaskulær rekanalisering og stenting av bekkenvene (11). Kirurgisk behandling av dyp venøs refluks varierer avhengig av etiologien. Ved primær (ukjent årsak, familiær belastning) kronisk venøs insuffisiens er ekstern eller intern klaffeplastikk indisert, mens det hos pasienter med sekundær (posttrombotisk) kronisk venøs insuffisiens er nødvendig med veneklafftransplantasjon eller veneklaffkonstruksjon kombinert med transposisjon. Ve- nøs obstruksjon behandles endovaskulært med rekanalisering og stenting.

Pre-, intra- og postoperativ antikoagulasjon gis i forbindelse med rekonstruktiv dyp venekirurgi i form av lavmolekylært heparin fra kvelden før operasjon og i seks måneder, dosert etter kroppsvekt. Pasienter med trombofili får livslang antikoagulasjonsbehandling med warfarin (12).

De to variablene som definerer klinisk suksess etter rekonstruktiv dyp venekirurgi, er sårtilheling og symptombedring tre måneder etter prosedyren. Symptombedring betyr stort sett at pasienten kan gjenoppta arbeid og fysisk aktivitet. Klinisk suksess er relatert til et godt primært kirurgisk resultat og rekonstruksjonens holdbarhet $(10,13)$. Holdbarhet defineres som antall måneder en rekonstruksjon holder seg suffisient verifisert med fargedupleksundersøkelser. Tabell 1 viser langtidsresultater i form av holdbarhet i de utvalgte publikasjonene (7, 8, 10, 13-15). Sårtilheling etter rekonstruktiv dyp venekirurgi er rapportert å kunne oppnås i $60-78 \%$ av tilfellene og klinisk bedring hos $90 \%$ av pasientene. Median sårfri periode etter rekonstruktiv dyp venekirurgi synes å være lengre hos pasienter med primær kronisk venøs insuffisiens, 54 måneder (12-72 måneder) enn hos pasienter med sekundær kronisk venøs insuffisiens 18 måneder (6-84 måneder).

Mens veneklaffkirurgi er en prosedyre for å hindre venøs refluks, behandles venøs obstruksjon i bekkenet med endovaskulær rekanalisering og stentimplantasjon. Primær åpenhet (dvs. åpenhet uten hendelser etter prosedyren) er etter tre og seks år henholdsvis $80 \%$ og $57 \%$. Sekundær åpenhet (dvs. der okklusjon har oppstått og en ny prosedyre var nødvendig) er etter tre og seks år henholdsvis $90 \%$ og $86 \%(11,16)$.

Masuda \& Kistner har rapportert den lengste oppfølgingen etter antirefluksrekonstruksjon, med en median på ti år (14). Ti års ku-

\section{Hovedbudskap}

- Rekonstruktiv dyp venekirurgi kan være aktuelt hos pasienter med kroniske venøse leggsår

- Slik kirurgi er et etablert tilbud i Norge

- Sårtilheling etter tre måneder oppnås hos $60-78 \%$

- Nøye preoperativ venefysiologisk utredning er nødvendig 


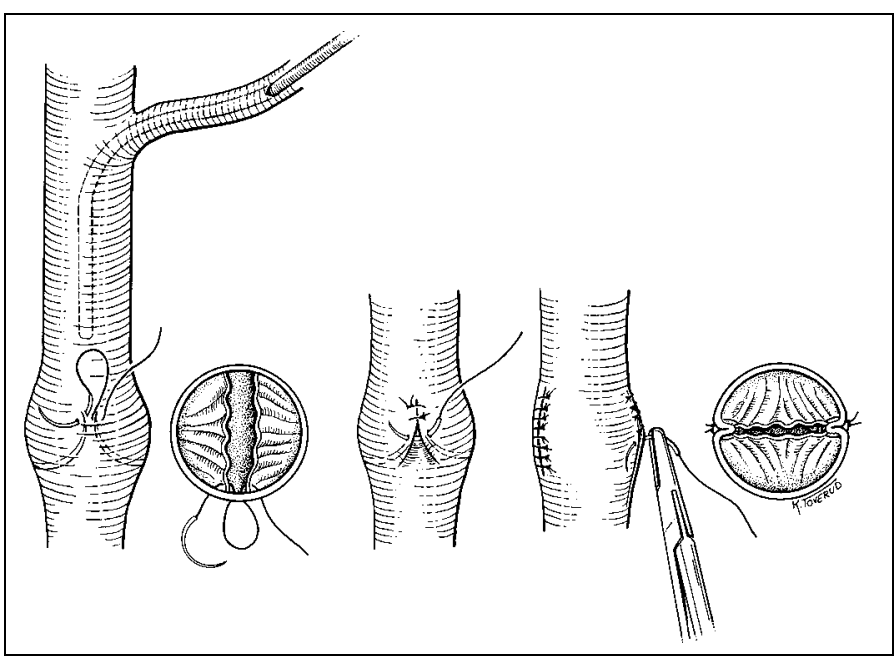

Figur 1 Ekstern veneklaffplastikk: Flere suturer plasseres utenfra gjennom veneveggen og innstramning av klaffene fører til normal klaffefunksjon. Angioskopi med et 2,8 mm skop tillater vurdering av klaffefunksjon før og etter plastikken $(7,10)$. Illustrasjon Kari C. Toverud, MS CMI (sertifisert medisinsk illustratør). Gjengitt med tillatelse

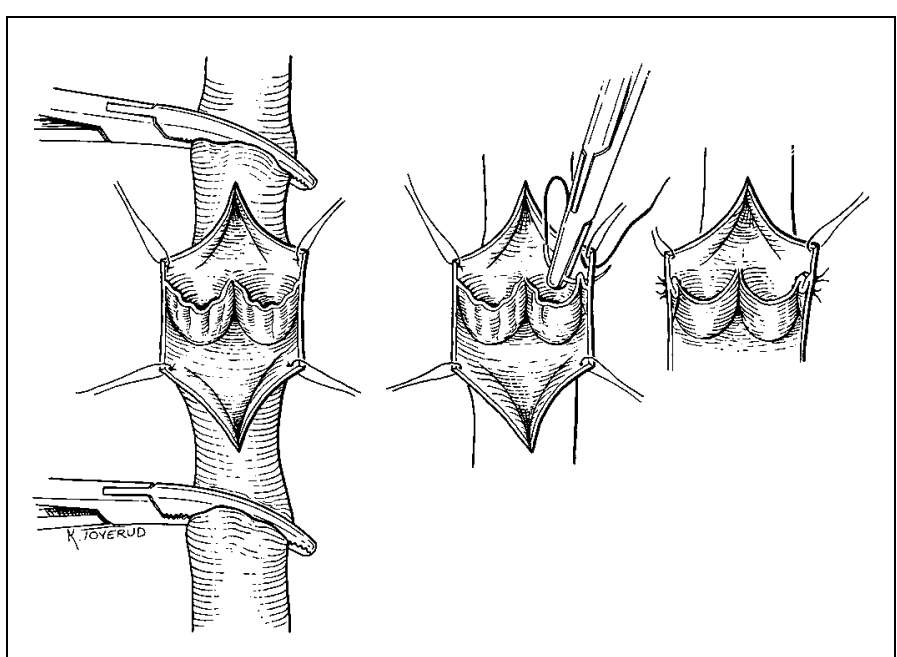

Figur 2 Intern veneklaffplastikk: Venen åpnes på langs (venotomi) for å visualisere veneklaffene. Slakke klaffer innstrammes med suturer inn mot veneveggen. Illustrasjon Kari C. Toverud, MS CMI Isertifisert medisinsk illustratør). Gjengitt med tillatelse mulativ klinisk suksess var klart bedre hos pasienter med primær kronisk venøs insuffisiens $(73 \%)$ enn hos pasienter med sekundær insuffisiens (43\%). Andre studier dokumenterer også bedre resultater hos pasienter med sekundær venøs insuffisiens (13).

Noen forfattere hevder at intern veneklaffplastikk har lengre holdbarhet enn ekstern veneklaffplastikk. Flere rekonstruksjoner i multiple nivåer synes å bedre langtidsresultater etter rekonstruktiv dyp venekirurgi $(10,13)$.

Ifølge våre observasjoner oppnås i større grad klinisk suksess og lengre holdbarhet hos pasienter med postoperativ reduksjon av ambulatorisk venetrykk på $\geq 20 \mathrm{~mm} \mathrm{Hg}$. Rekonstruksjon i v. poplitea synes å være vesentlig for å oppnå hemodynamisk bedring og forlenger holdbarheten av rekonstruksjonen (10).

\section{Diskusjon}

Patofysiologien ved kronisk venøs insuffisiens kan være komplisert både med persisterende okklusjoner etter dyp venetrombose og med destruert veneklaffapparat med venøs refluks i multiple nivåer. I alvorlige tilfeller med invalidiserende symptomer i ekstremiteten med eller uten leggsår har man tradisjonelt behandlet pasientene konservativt med stram kompresjon, elevasjon og ev. sårstell. Slike tiltak representerer fremdeles bærebjelken i behandlingen av kronisk venøs insuffisiens. Rekonstruktiv dyp venekirurgi har hatt en begrenset plass i behandlingen av pasienter med kronisk venøs insuffisiens pga. behov for nøyaktig preoperativ venefysiologisk utredning og teknisk krevende operasjoner. Dessuten er kronisk venøs insuffisiens et ikke-prioritert område på de fleste karkirurgiske sentre.

Seleksjonen av pasienter egnet for operative tiltak er utfordrende fordi den krever tilgang til et etablert sirkulasjonsfysiologisk laboratorium, kunnskap om venefysiologiske utredningsmetoder, tolking av venøs pa- tofysiologi og klart definerte indikasjoner for kirurgi. Det er internasjonal enighet om å anbefale sentralisering av slik virksomhet dels med årsak i volum og dels for å konsolidere et slikt utrednings- og behandlingstilbud før kunnskapen utbres til andre universitetsmiljøer. Man forventer en økning i behovet for utredning og behandling av kronisk venøs insuffisiens fordi tilstanden medfører redusert livskvalitet, sykmelding av yrkesaktive og høye sosioøkonomiske utgifter. Publiserte resultater oppnådd etter rekonstruktiv dyp venekirurgi i Norge er tilfredsstillende og sammenliknbare med internasjonale resultater $(7,10)$.

\section{Fremtidig utvikling}

Endovaskulære teknikker har gjennomgått en svært rask utvikling i løpet av de siste årene. Disse perkutane prosedyrene er mindre invasive, mer skånsomme for pasientene og noen ganger mindre krevende teknisk. Flere forsøk på å lage en stentmontert veneklaff som kan implanteres perkutant, har vært rapportert. Ingen har lyktes fullt ut. Utfordringen består i å lage et implantat som er ikketrombogent, ikke-inmunogent og som ikke migrerer med tiden. (17). Konstruksjon av en ny veneklaff ved bruk av den fortykkede posttrombotiske intima er et interessant konsept og representerer et alternativ hos pasienter med sekundær kronisk venøs insuffisiens der manglende donorsted for auto-veneklafftransplantasjon er et problem (18). Større materialer og langtidsresultater bør gi svar på holdbarheten av denne teknikken.

\section{Konklusjon}

Rekonstruktiv dyp venekirurgi er per i dag et reelt alternativ for pasienter med kronisk

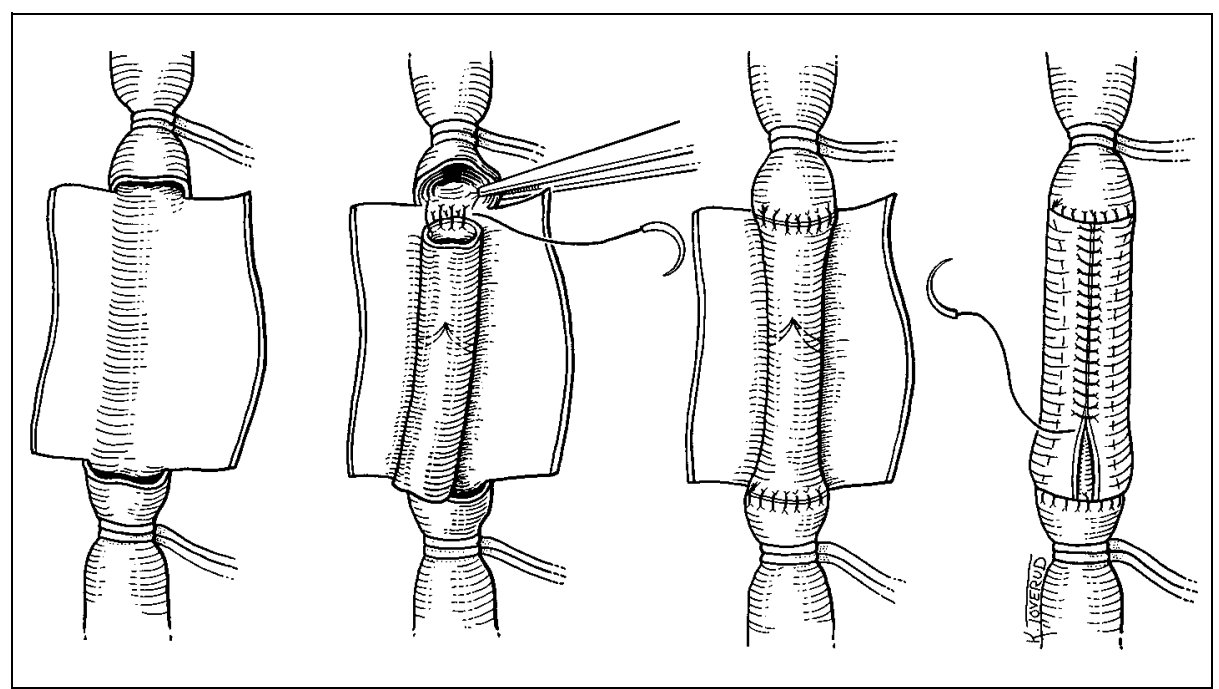

Figur 3 Transplantasjon: Et venesegment med en normalt fungerende veneklaff transplanteres til en insuffisient dyp vene. Segmentet interponeres ved «in-lay»-teknikk slik at det native karet kan lukkes rundt transplantatet som en forsterkende hylse (10). Illustrasjon Kari C. Toverud, MS CMI (sertifisert medisinsk illustratør). Gjengitt med tillatelse 
Tabell 1 Andel pasienter (prosent) med suffisient dyp venøs rekonstruksjon tre, fem, sju og ti år etter kirurgi for primær (PKVI) eller sekundær (SKVI) kronisk venøs insuffisiens. Primær kronisk venøs insuffisiens er medfødt eller oppstår på arvelig grunnlag, mens sekundær kronisk venøs insuffisiens oppstår etter dyp venetrombose

$$
3 \text { år }
$$

PKVI SKVI

Raju og medarbeidere (13)

Masuda og medarbeidere (14)

Eriksson og medarbeidere (8)

Perrin og medarbeidere (15)

Rosales og medarbeidere $(7,12)$

68

$68 \quad 42$

$-\quad-$

$-$

$-\quad-$

$64 \quad 47$

\section{5 år}

10 år

PKVI SKVI

PKVI SKVI

PKVI SKVI

$50 \quad 40$

- $\quad-$

$70 \quad 31$

62

52

$\begin{array}{cccc}- & - & 52 & 32 \\ - & - & 73 & 43 \\ - & - & - & - \\ - & 53 & - & - \\ - & 40 & - & -\end{array}$

venøs insuffisiens der konvensjonell terapi (kompresjon og kirurgisk sanering av overflatisk/perforant insuffisiens) ikke har lyktes. Gevinsten er sårfrie perioder og tilbakeføring til arbeidslivet.

\section{Oppgitte interessekonflikter: Ingen}

\section{Litteratur}

1. Nelzen O, Bergqvist D, Lindhagen A. The prevalence of chronic lower-limb ulceration has been underestimated: results of a validated population questionnaire. Br J Surg 1996; 83: 255-8.

2. Ruckley CV. Socioeconomic impact of chronic venous insufficiency and leg ulcers. Angiology 1997; 48: 67-9.

3. Tennvall GR, Andersson K, Bjellerup $M$ et al. Venösa bensår kan behandlas både bättre och bil- ligare. Beräkning av årlige kostnader baserad på enkätstudie. Läkartidningen 2004: 101: 1506-13.

4. Kistner RL, Eklof B, Masuda EM. Diagnosis of chronic venous disease of the lower extremities the «CEAP» classification. Mayo Clin Proc 1996: 71: 338-45.

5. Eklof B, Rutherford RB, Bergan JJ et al. Revision of the CEAP classification for chronic venous disorders: consensus statement. J Vasc Surg 2004; 40: $1248-52$.

6. Slagsvold CE, Stranden E. Venøse leggsår. Tidsskr Nor Lægeforen 2005; 125: 891-4.

7. Rosales A, Slagsvold CE, Kroese AJ et al. External venous valve plasty (EVVP) in patients with primary chronic venous insufficiency (PCVI). Eur J Vasc Endovasc Surg 2006; 32: 570-6.

8. Eriksson I. Reconstructive surgery for deep vein Surg 1990; 4: 211-8.

9. Kistner RL, Eklof B, Masuda EM. Deep venous valve reconstruction. Cardiovasc Surg 1995; 3: 129-40. valve incompetence in the lower limb. Eur J Vasc
10. Rosales A, Jorgensen JJ, Slagsvold CE et al. Venous valve reconstruction in patients with secondary chronic venous insufficiency. Eur J Vasc Endovasc Surg 2008; 36: 466-72.

11. Neglen P. Hollis KC, Olivier J et al. Stenting of the venous outflow in chronic venous disease: longterm stent-related outcome, clinical, and hemodynamic result. J Vasc Surg 2007; 46: 979-90.

12. MacKenzie RK, Ludlam CA, Ruckley CV et al. The prevalence of thrombophilia in patients with chronic venous leg ulceration. J Vasc Surg 2002; 35: 718-22.

13. Raju S, Fredericks RK, Neglen PN et al. Durability of venous valve reconstruction. Techniques for «primary» and postthrombotic reflux. J Vasc Surg 1996; 23: 357-66

14. Masuda EM, Kistner RL. Long-term results of venous valve reconstruction: a four- to twentyone-year follow-up. J Vasc Surg 1994: 19: $391-403$

15. Perrin M. Surgery for deep venous reflux in the lower limb. Praxis 2006; 95: 464-8.

16. Neglen P. Chronic deep venous obstruction: definition, prevalence, diagnosis, management. Phlebology 2008; 23: 149-57

17. Pavcnik D, Uchida B, Kaufman J et al. Percutaneous management of chronic deep venous reflux: review of experimental work and early clinical experience with bioprosthetic valve. Vasc Med 2008; 13: 75-84.

18. Maleti $\mathrm{O}$, Lugli M. Neovalve construction in postthrombotic syndrome. J Vasc Surg 2006; 43: 794-9.

Manuskriptet ble mottatt 5.2. 2009 og godkjent 13.10. 2009. Medisinsk redaktør Odd Terje Brustugun. 